\begin{tabular}{c}
\hline KeMAS 15 (3) (2020) 372-381 \\
Jurnal Kesehatan Masyarakat
\end{tabular}

\title{
Characteristics of Shoes with Musculoskeletal Complaints on Foot and Ankle of Sales Promotion Girl
}

\author{
Mas Amaliyah ${ }^{\bowtie}$, Isa Ma’rufi, Reny Indrayani \\ Occupational Health and Safety Studies, Faculty Of Public Health, University of Jember, Indonesia
}

\begin{tabular}{l} 
Article Info \\
\hline Article History: \\
Submitted July 2018 \\
Accepted December 2019 \\
Published March 2020 \\
\hline Keywords: \\
Musculoskeletal \\
Complaints on Foot and \\
Ankle, FAOS, Charac- \\
teristics of Shoes, SPG. \\
DOI \\
https://doi.org/10.15294/ \\
kemas.v15i3.14972
\end{tabular}

\begin{abstract}
Musculoskeletal complaints are a series of aches in the tendons, muscles, and nerves due to activities with high repetition rates resulting in tissue damage and pain in the muscles. Musculoskeletal complaints are experienced by many female workers due to work demands. Job demands such as the obligation to use high heels when working. Jobs related to the use of high heels are sales promotion girl (SPG). This study uses a quantitative approach. This type of research is observational analytic with cross sectional design. The assessment of musculoskeletal complaints in this study used the Foot and Ankle Outcomes Score (FAOS) questionnaire. Based on the results of the Spearman test factors associated with musculoskeletal complaints on feet and ankles of SPG at Golden Market Jember include individual factors consisting of length of work $(\rho=0,000 ; \mathrm{r}=0.617$; negative direction), BMI ( $\rho=0.022 ; \mathrm{r}=0.314$; unidirectional), and sports habits $(\rho=0.045 ; \mathrm{r}$ $=0.617$, opposite). The work factor is static position $(\rho=0,000 ; \mathrm{r}=0.530$; opposite). Shoe characteristic variables consist of shoes type $(\rho=0.022 ; \mathrm{r}=0.313$, opposite), duration of use ( $\rho=0,000 ; r=0.547$; direction), high heels $(\rho=0,000 ; r=0.855$; direction $)$, and suitability shoe size ( $\rho=0,000 ; r=0.584$; unidirectional). Factors not related to musculoskeletal complaints on the feet and ankles are age ( $\rho=0.027 ; r=0.850$; unidirectional).
\end{abstract}

\section{Introduction}

The work environment has the potential to pose a risk of danger, one of which is the danger of ergonomic factors. This is a study of the relationship between work and the human body, which means organizing work and work areas according to workers' needs. Ergonomic dangers can cause musculoskeletal complaints such as muscle pain, fatigue and even injury (Slovak et al., 2009). Based on Labor Force Survey data in the Health and Safety Executive (HSE) (2017), musculoskeletal cases in 2016 in the United Kingdom were 507,000 workers. They experience musculoskeletal disorders and of these, musculoskeletal disorders are found in the lower limbs. Women are more likely to experience musculoskeletal disorders than other occupational diseases. As many as $58 \%$ of women experience musculoskeletal disorders related to their work. In addition, women are $42 \%$ more risk than men (Nicot, 2008).

In general, factors that have the potential to cause musculoskeletal complaints include: 1) occupational factors (odd composition, static position, workload, duration of work); 2) individual factors (age, sex, length of work, body mass index, and exercise habits); 3) work environment factors (temperature, humidity, vibration, and lighting) (Occupational Safety and Health Administration (OSHA), 2007). Specific factors that influence musculoskeletal disorders in the biomechanical system in a woman's body such as age, type of work, job demands (Nicot, 2008). The job demands are 
regulations that require female workers to use high heels when working. According to a survey of female workers in the United States, there are about $59 \%$ of women using high heels for about one to eight hours per day (Kim, 2000). 80\% of female workers in the UK who use high heels experience leg muscle pain (Dewi, 2014). The factor that causes musculoskeletal complaints in high-heeled users is the shoe selection error. These characteristics include shoe models (flat, heels, wedges), high heel shoes, and the suitability of shoe size with feet (Nuryaningtyas \& Tri, 2014).

The use of high-heeled shoes will change the pattern of the user's body load distribution to be almost the same on the front of the foot and the back of the foot. High heels affect the user's posture, especially in the lower limbs and spine. Users tend to involuntarily bend their knees forward to resist the distribution of altered body loads (Silva, et al., 2013). Changes in the body's impact point affect the kinetic and joint increase the risk of pain in the patellofemoral and ankle (Smallwood, et al., 2013). The design of footwear for standing work is that the size of the footwear must be looser than the size of the sole of the foot and there is no strong restraint on the ankle ligaments so that the skeletal muscles do not easily experience fatigue. The convenience of using a tool depends on the suitability of the size of the tool with the size of the tool with a human size.

One of the jobs in Indonesia related to the use of high heels is sales promotion girls (SPG). SPG's duty is to serve and provide information about certain products. They are required to stand continuously for at least 6 hours a day using high heels. One of them is SPG Golden Market in Jember. Based on the results of interviews conducted by researchers, SPG experienced pain in the heel and feet. In accordance with the results of mapping on pain with the Nordic body map, the body parts of SPG $\mathrm{X}$ shopping center workers Depok city in 2012 who experienced the most pain symptoms were right and left calves $(83.33 \%)$ while the right and left legs (56.67). The results of the initial randomized survey of researchers in several shopping centers in Jember with the Foot and Ankle Outcome Score (FAOS) questionnaire obtained that from 10 respondents stated $60 \%$ felt mild musculoskeletal complaints.

According to interviews with Human Resource Development (HRD) and Golden Market Jember supervisors, it has a unique work system that SPG conducts a rolling booth system every day. The system requires SPG to know not only one product but all products sold at the shopping center. High workload can be seen from the duration of work which has a longer duration than other shopping centers, which is around 9 hours of work while in other shopping centers around 7 hours of work. Golden Market Jember has a Standard Operational Procedure (SOP) that is applied as a rule regarding the obligation of SPG to use high heels of at least $5 \mathrm{~cm}$. Based on these problems, this shows that the Golden Market Jember SPG is at risk of experiencing musculoskeletal complaints on the feet and ankles due to the use of uncomfortable work equipment, one of which is the use of high heels. The purpose of this study was to analyze the relationship of shoe characteristics with musculoskeletal complaints on foot and ankle sales promotion girls (SPG) at Golden Market Jember.

\section{Method}

This type of research used in this research is observational analytic research with a quantitative approach. The research design used was cross-sectional. Measurement of variables and data collection is done in a certain time. This research was conducted on female workers who work as SPG at Golden Market Jember. The research sample of 53 people from a total population of 60 people taken by proportional random sampling. Population is divided into several places or sections such as markets, shops, shoes, and toys. Exclusion criteria are such as respondents having a job as a sales promotion girl elsewhere outside Golden Market Jember, respondents being pregnant, respondents having a history of illness, and injuries or trauma related to muscle and skeletal / ankle conditions before working as employees at the Golden Market Jember.

The independent variables in this study are individual factors, occupational factors, and shoe characteristics. The dependent variable in this study was musculoskeletal complaints in the legs and ankles. The data used in this study consisted of two types, namely primary 
and secondary. Primary data in this study are in the form of information or explanations from the results of interviews, observations, and documentation studies. Secondary data in this study sourced from printed books, electronic books, journals / articles containing theories that are relevant to the object under study, and the results of previous studies. Data collection instruments for musculoskeletal complaints data collection on the feet and ankles are FAOS (Foot and Ankle Outcome Score) questionnaire.

\section{Result and Discussion}

In this study, the individual factors studied consisted of age, length of work, nutritional status, and exercise habits undertaken by respondents.

Based on the age category of the labor force according to the Central Statistics Agency (BPS) in 2017, the results obtained in table 1 show that most respondents have ages in the category of 20-24 years, 31 people with a percentage of $58.5 \%$. The data of work duration obtained in table 1 above shows that the length of work of the respondents is mostly in the 1-2 year group with a percentage of $41.5 \%$. The results of the nutritional status data obtained in table 1 is that most respondents have normal weight nutritional status with BMI values $>18.5$ - 25.0 of 29 people with a percentage of $54.7 \%$. The results of sports habits research found in table 1 are that the majority of respondents did not do regular exercise, 42 people with a percentage of $79.2 \%$.

The results obtained show that the majority of respondents were in a static position of 33 people with a percentage of $62.3 \%$.

Variables of characteristics of shoe are variables that arise due to equipment used when the respondent works. These variables include the type of shoes used, the length of shoes used, the height of the heel, and the suitability of the foot size.

The results of the type of shoes used by respondents based on table 2 shows that the respondents used the most types of high heels as many as 30 people with a percentage of $56.6 \%$. The results of the old shoe usage data described in table 2 show that there were 32 people or $60.4 \%$ working with one work shift while respondents who worked one work shift plus overtime were 21 people or $39.6 \%$. The results of data on the height of the heels obtained in table 2 show that respondents using shoes with the height of less than $5 \mathrm{~cm}$ were 21

Table 1. Frequency Distribution based on Individual Factors of SPG at Golden Market Jember in 2018

\begin{tabular}{|c|c|c|}
\hline Individual Factor & $\mathrm{n}$ & $\%$ \\
\hline \multicolumn{3}{|l|}{ Age } \\
\hline $15-19$ years & 14 & 26,4 \\
\hline $20-24$ years & 31 & 58,5 \\
\hline $25-29$ years & 7 & 13,2 \\
\hline $30-34$ years & 1 & 1,9 \\
\hline Total & 53 & 100,0 \\
\hline \multicolumn{3}{|l|}{ Length of work } \\
\hline$<1$ years & 19 & 35,8 \\
\hline $1-2$ years & 22 & 41,5 \\
\hline$>2$ years & 12 & 22,6 \\
\hline Total & 53 & 100,0 \\
\hline \multicolumn{3}{|l|}{ Nutrition Status (weight) } \\
\hline$<17,0 \quad$ : Skinny Weight & 10 & 18,9 \\
\hline $17,0-18,5$ : Skinny Light Level & 11 & 20,8 \\
\hline$>18,5-25,0:$ Normal & 29 & 54,7 \\
\hline$>25,0-27,0:$ Fat Light Level & 1 & 1,9 \\
\hline$>27,0 \quad:$ Fatty Weight & 2 & 3,8 \\
\hline Total & 53 & 100,0 \\
\hline \multicolumn{3}{|l|}{ Exercise Habbits } \\
\hline Yes & 11 & 20,8 \\
\hline No & 42 & 79,2 \\
\hline Total & 53 & 100,0 \\
\hline
\end{tabular}

Source: Primary Data, 2018 
Table 2. Frequency Distribution based on Characteristics of SPG Shoe at the Golden Market Jember in 2018

\begin{tabular}{lll}
\hline Variables of shoe characteristic & $\mathrm{n}$ & $\%$ \\
\hline Shoe type & 7 & 13.2 \\
Flat shoes & 30 & 56.6 \\
High heels & 16 & 30.2 \\
Wedges High Heels & 53 & 100.0 \\
Total & & \\
Length of shoes used & 32 & 60.4 \\
One Work Shift & 21 & 39.6 \\
One Work and Overtime Shift & 53 & 100.0 \\
Total & & \\
Height of the heel & 21 & 39.6 \\
$<5$ cm & 15 & 28.3 \\
5 cm & 17 & 32.1 \\
$>5$ cm & 53 & 100.0 \\
Total & & \\
Suitability of the foot size & 34 & 64.2 \\
Suitable & 19 & 35.8 \\
Not suitable & 53 & 100.0 \\
\hline
\end{tabular}

Source: Primary Data. 2018

people with a percentage of 39.6. The results of shoe size suitability data obtained in table 3 shows that respondents used shoes according to the size of the feet they have are 34 people with a percentage of $64.2 \%$. Then, respondents who use shoes that do not match their size are 19 people or $35.8 \%$.

Table 3 Frequency Distribution based on Musculoskeletal Complaints on SPG at the Golden Market Jember in 2018

\begin{tabular}{lll}
\hline Musculoskeletal complaints & $\mathrm{n}$ & $\%$ \\
\hline No complaint & 0 & 0 \\
Light & 22 & 41,5 \\
Medium & 21 & 39,6 \\
Serious & 10 & 18,9 \\
Extreme & 0 & 0 \\
Total & 53 & 100,0
\end{tabular}

Source: Primary Data, 2018

The results obtained in table 3 show that respondents experiencing complaints at a mild level are 22 people with a percentage of $41.5 \%$, while at the level of complaints there are no complaints and extreme is no one feels a complaint.

The results of the Spearman test analysis of age variables with foot and ankle musculoskeletal complaints as in table 4 show that the relationship between age and musculoskeletal complaints on foot and ankle has a $\mathrm{p}$-value of 0.850 , these values indicate an insignificant $p$-value of $>\alpha(\alpha(0.05)$. this means that there is no relationship between age variables with foot and ankle musculoskeletal complaints in study respondents. The coefficient of correlation coefficient which is 0.027 shows that it is very weak with a positive correlation direction.

Karl Spearman's test results on the length of work variable with complaints of musculoskeletal foot and ankle as in table 4 obtained a $p$-value of 0,000 . The $p$-value $<\alpha$, this means that the two variables have a significant relationship with the correlation level $(r)$ of 0.617. This means that the relationship has a strong degree of correlation. The direction of the correlation held in the relationship is negative.

Spearman's test results of nutritional status variables with foot and ankle musculoskeletal complaints as in table 4 show that IMT variable with musculoskeletal complaints obtained p-value of 0.022 , the $\mathrm{p}$-value $<\alpha(0.05)$, this means that both variables are contained significant relationship with the level of correlation ( $\mathrm{r}$ ) of 0.314 . This means that the level of correlation possessed is a weak level. The direction of the correlation is positive or unidirectional.

Karl Spearman's test results on variable exercise habits with musculoskeletal complaints of the feet and ankles as in table 4 obtained a 
Table 4. Results of Analysis of Individual Factors with MSDS Complaints on the SPG at Golden Market Jember in 2018

\begin{tabular}{lllll}
\hline Category of MSDS & & & & \\
\hline Spearman's rho & Age & Correlation Coefficient & 1000 & .027 \\
& Length of work & Sig. (2-tailed) &. & .850 \\
& Correlation Coefficient & 1000 & $-.617^{* *}$ \\
& IMT & Sig. (2-tailed) &. & .000 \\
& Correlation Coefficient & 1000 & $.314^{*}$ \\
& Exercise habbit & Sig. (2-tailed) &. & .022 \\
& Correlation Coefficient & 1000 & .277 \\
& Sig. (2-tailed) &. & .045 \\
& N & 53 & 53 \\
\hline
\end{tabular}

Source: Primary Data, 2018

p-value of 0.045 . When compared with the alpha value is $<\alpha(0.05)$, this means that the two variables have a significant relationship with the correlation level $(r)$ of 0.617 . This means that having a strong level of relationship. The direction of the relationship between the two variables is negative or opposite.

The Spearman test results show that the static position variable with the musculoskeletal complaint variable on the foot and ankle has a p-value of $0,000<\alpha(0.05)$, this means that the two variables are significantly related. The correlation level ( $\mathrm{r}$ ) of the two variables is 0.530 , which means the correlation level is moderate. The direction of the relationship is negative or not in the same direction. This means that the more often the respondents are in a static position, the more respondents will tend to experience musculoskeletal complaints of the feet and ankles.

The results of the Spearman test on shoe type variables with foot and ankle musculoskeletal complaints that have been done on shoe type variables and musculoskeletal complaints obtained p-value of $0.022<a$ (0.05). This means that the two variables have a significant relationship with a correlation level ( $r$ ) of 0.313 or the correlation strength is weak. The direction of the correlation is negative or opposite, which means the smaller the surface area of the bottom type of shoes used by the respondent, the greater the level of musculoskeletal complaints on foot and ankle experienced by the respondent.

Based on table 5, the results of the Spearman test on the variable length of shoe use with complaints of musculoskeletal foot and ankle that have been carried out on both variables obtained a p-value of 0,000 . This means that it has significance on both variables. The correlation strength possessed by the two variables is 0.547 which means that the correlation strength between the two variables is at a moderate level and the direction of the relationship between the two variables is positive or unidirectional. Thus, the longer the respondent works, the higher the perceived musculoskeletal complaints.

The results of the Spearman test on the variable height of shoes with complaints of musculoskeletal foot and ankle as in table 5 obtained the $p$-value of $0,000<\alpha(0.05)$. This means that the two variables have a significant relationship. The correlation strength possessed by both variables is 0.855 which means that both variables have a very strong level of correlation power. The direction of the positive correlation or the higher the heels used, the higher the risk of perceived foot and ankle musculoskeletal complaints.

The Spearman test results regarding the suitability of shoe size with complaints of musculoskeletal complaints on foot and ankle as in table 5 obtained a p-value of 0,000 $<a(0.05)$. This means that the two variables have a significant relationship. The correlation strength ( $r$ ) owned by the two variables is 0.584 , which means that the two relationship variables have a moderate level of correlation power. The direction of the relationship between the two variables is positive or unidirectional, the more inappropriate the size of the shoes used or the size of shoes used by the respondent, the higher the level of musculoskeletal foot and ankle complaints felt by the respondent.

Most of the age of respondents in this study were in the age group 20-29 years. This result is due to the reason many companies 
Table 5. Results of Analysis of Relationships on Shoe Characteristics variables with MSDS Complaints of SPG at Golden Market Jember in 2018

\begin{tabular}{lllll}
\hline Category of MSDS & & & & \\
\hline Spearman's rho & Shoe types & Correlation Coefficient & 1000 & -.313 \\
& & Sig. (2-tailed) &. & .022 \\
& Length of shoe used & Correlation Coefficient & 1000 & .547 \\
& & Sig. (2-tailed) &. & .000 \\
& Height of the heel & Correlation Coefficient & 1000 & .547 \\
& & Sig. (2-tailed) &. & .000 \\
& Suitability of the & Correlation Coefficient & 1000 & .855 \\
& & Sig. (2-tailed) &. & .000 \\
& & $\mathrm{~N}$ & 53 & 53 \\
\hline
\end{tabular}

Source: Primary Data of Respondents Research Questionnaire of SPG at Golden Market Jember

choose workers with job qualifications that have attractive, easy, and active appearance so that workers are dominated by workers under the age of 25 years. A young worker tends to be more sensitive, open, and more flexible to changes and new things compared to old age (Robbin in Megawati, 2014). The company prefers young workers related to product promotion and marketing jobs because younger workers will understand new things and be able to convey information about the product more flexibly. In this study, there were workers with 17 years of age which were included in the age category of the labor force. Workers under the age of 18 are child laborers. The company must do several things before hiring child labor, among others must have a parent's permission, work in the category of light work, do not disturb the school hours of the child labor and do not employ no more than 3 hours per day (Ministry of Manpower and Transmigration of the Republic of Indonesia, 2013).

Most respondents have worked as SPG Golden Market for 1-2 years. This shows that SPG has become a permanent employee at Golden Market Jember and has passed the training period for 6 months. The training period here serves to train workers to adjust their body conditions to the portion of work to be done. The average worker is already familiar with equipment such as uniforms and high heels that are used, but in the working age group there is still a risk of finding musculoskeletal complaints. The work period contributes to the accumulation of a person's activities carried out in a long time and continuously with a position that holds a pressure one of the muscles of lower extremities so that disruption occurs in that body part (Andreani, 2013).

In this study, it is known that most respondents had normal weight categories. This relates to demands from Golden Market management for the SPG to maintain the weight balance they have. However, at the time of the study, there were still workers who had light weight and not too much fat. This is in line with the health goals of workers in reducing the risk of musculoskeletal complaints. Respondents with a BMI category of fat have a high risk of experiencing musculoskeletal complaints compared to workers who have a normal or thin category BMI. Musculoskeletal complaints of the feet and ankles will be experienced by workers with a BMI level of fat because there is a pressure derived from body weight on the lower extremity muscle higher than workers who have normal weight or thin, so that the body pressure they have is getting smaller (Tarwaka, 2015)

Exercise is very important for the prevention of certain diseases such as musculoskeletal complaints in the muscles of workers. This can be seen in the results of the study which showed that most respondents did not have exercise habits. But there are some respondents who have exercise habits too. Worker's exercise habits cause a reduction in the risk of workers experiencing musculoskeletal complaints. Regular exercise can improve quality of life, prevent osteoporosis, and various skeletal diseases. Lack of sports activities can reduce the supply of oxygen to the muscles so that in that section experiencing complaints to pain. In addition, sports activities such as stretching work to stretch the muscles that have been used for a certain period of time (Andini, 
2015).

Most respondents work in a static position. Static positions are carried out when the respondent does work such as arranging clothes, recording incoming and outgoing goods, making reports. This position is most experienced by respondents when there are no customers or buyers. In the type of SPG work, a static position that is often done is standing still using the same footstool for at least one minute. This has a great risk for workers in the occurrence of musculoskeletal complaints, especially in the lower extremity muscle. When the body is in a static position, there will be a blockage in the flow of blood and result in that part of lack of oxygen and glucose from the blood. In addition, the body will produce metabolic waste such as lactic acid that cannot be transported out due to disrupted blood circulation so that it builds up and causes pain (Ulfah, 2014).

The type of shoes used by most respondents is the model of high heels. Shoe user balance when wearing shoes depends on the base of the shoe being used. Shoe wearers must adapt to the shoes used, high heels, will make the postural plantar legs experience excessive flexion movements so that the center of body mass shifts to maintain stability when walking and standing (Permatasari, 2017).

Some respondents work with one normal work shift, but in this study obtained several respondents work one shift plus overtime. This resulted in the group of respondents using high heels longer, so they were more at risk of experiencing musculoskeletal complaints. The longer the duration of work performed, the longer the recovery time required for the worker. Workers who have a longer work duration require a long time for their muscles to recover after doing the work. This results in workers often feeling more pain in their bodies after hours of overtime than after working with normal time (NIOSH, 1993).

Most workers wear shoes with $<5 \mathrm{~cm}$ in height but if the other two categories are added together the results show that more respondents wear shoes with a height of $\geq 5 \mathrm{~cm}$. According to previous studies, the most SPG results are users of high heels with a size of $5 \mathrm{~cm}$ and > $5 \mathrm{~cm}$. At this height, respondents are at risk of experiencing musculoskeletal complaints in lower extremity muscles. This is in accordance with the theory of pressure or Pascal's Law that the wider the surface area of the object the less pressure there is. This is the same as a high-heeled shoe base, the higher the shoe the smaller the surface area of the shoe base, so that the resulting foot pressure is greater (Purba, 2015).

In this study, it was found that the average SPG worker used shoes that matched his foot size. The size of shoes that fit the feet will cause comfort for its users. Respondents who wear shoes of inappropriate size have a higher risk of experiencing pain in their feet. Shoes have a high compatibility with the wearer which is important to reduce the emergence of hazards due to pressure on the foot so that the appearance of complaints on the feet depends on the suitability between shoe size and anthropometry (Dewi, 2014).

In this study, musculoskeletal complaints are subjective complaints felt by respondents on the feet and ankles. In the results of the study, it was found that the musculoskeletal complaints felt by most respondents at mild and moderate levels. These results indicate that the level of complaints felt by respondents who work as SPGs at Golden Market Jember are still included as temporary complaints (reversible), complaints that occur when the muscles receive a static load. This will disappear if the loading on the muscle is stopped so that the muscle condition can still return to normal (Tarwaka, 2015).

The results of the age relationship test with musculoskeletal complaints on the feet and ankles there was no significant relationship with a p-value of 0.850 . The degree of correlation strength is very weak with the direction of the positive relationship. There is no significant relationship between ages with musculoskeletal complaints. Muscle pain usually occurs at a young age and some of these are productive ages. Young people under 35 years old have a high risk associated with musculoskeletal complaints because the age of the respondent has not been proportional to the length of time the respondent works as SPG (Dewi, 2013).

The length of work with musculoskeletal complaints has a significant relationship with 
the degree of correlation so it is said that the relationship has a strong correlation strength. The direction of the negative correlation which means that the longer the respondent works the smaller the musculoskeletal complaints felt by the respondent. The reason is the adaptation of the respondent's leg muscles within a certain work period. The length of work of SPG workers over $>3$ years has affected the muscles of adapters and the pain felt in the legs when wearing high heels is reduced. This is different from the initial SPG work while still adapting to body position when working with the use of work equipment (Sinta, 2014).

Spearman's test results on nutritional status with musculoskeletal complaints there is no significant relationship with the level of correlation at a weak level. The direction of positive or unidirectional correlation means that the greater the respondent's nutritional status category the greater the perceived musculoskeletal complaints. Comparison of body weight and height that is not ideal or exceeds the normal range assumes that body weight has exceeded the ability of the body's propping force so that it triggers the emergence of musculoskeletal complaints in the form of pain in muscles and joints (Sinta, 2014).

Sports habits with musculoskeletal complaints have a significant relationship. The strength of the correlation is shown at a strong level and has a negative or unidirectional direction. This means that the more respondents have good exercise habits the less musculoskeletal complaints they experience. Exercise habits will create muscle stretching activities. These activities make the muscles more flexible. This condition will help reduce discomfort due to tension, pain and even cramps that occur in the muscles of workers. In addition, this mobilizes the spine and surrounding soft tissue thereby increasing the overall range of motion and fluidity in the joints. If done routinely every day, it will help workers prepare their bodies for activities while working (Lestari, 2013).

The relationship between static position and musculoskeletal complaints variable has a significant relationship. The strength of the correlation in the relationship is at a moderate level and the direction of the relationship is negative or not in the same direction. This means that the more often the respondents are in a static position, the more respondents are likely to experience musculoskeletal complaints. This situation can occur due to the forced attitude on some parts of the skeletal muscles when the work position is standing continuously so that there is a static loading on the muscles in the skeletal muscle at most parts of the calf, thigh, and muscle extremities of the legs (Tarwaka, 2015).

The type of shoes with musculoskeletal complaints has a significant relationship. The strength of the correlation is at a weak level with a negative or opposite direction. This means that the smaller the surface area of the bottom of the respondent's right shoes the greater the musculoskeletal foot and ankle complaints experienced by the respondent. The use of high heels affects the occurrence of musculoskeletal complaints. This is caused by changes in the way of walking and balance. Changes in balance and gait occur due to excessive postural plantar adaptation. Increased lower extremity muscle activity and shift in center of body mass occur to increase stability when wearing high heels. The shift of the center of body mass affects the activity of paraspinal muscle so that there is a change in pressure on the muscle extremities of the respondent's feet (Permatasari, 2017).

High heels with musculoskeletal complaints have a significant relationship. The strength of the correlation in these relationships is a very strong level in the direction of a positive or unidirectional correlation. This means that the higher the heels used, the higher the level of foot and ankle musculoskeletal complaints felt. The higher the heels used, the narrower the surface area of the right. In accordance with the law of solid body pressure that if the surface area of an object gets narrower than the pressure caused on the object gets bigger (Purba, 2015).

The suitability of shoes with musculoskeletal complaints has a significant relationship. The strength of correlation (r) is at a moderate level with the direction of a positive or unidirectional relationship. This means that the more inappropriate the size of shoes used by the respondent the higher the level of complaints felt by the respondent. This is due to the design of the shoes which is very suitable that the size 
of the footwear must be looser than the sole of the foot and there is no strong restraint on the ankle ligaments. This can reduce the occurrence of skeletal muscle fatigue (Dewi, 2013). Good shoes are shoes that can hold feet (body) and feet are not bothered to hold shoes. The design of the shoe must be looser than the sole of the foot. Looser size shoes are meant to be shoes that have a distance or an empty space of about $1.2 \mathrm{~cm}$ between the longest finger the user has and the inside end of the shoe. This serves to shift the foot component when standing or walking (Santoso, 2004). Measurements can be made by inserting the tip of the index finger on the heel. If the distance is too narrow then look for a larger shoe size but if the distance of the index finger with the foot is too loose then it is better to look for a smaller shoe size.

\section{Conclusion}

Factors related to musculoskeletal complaints on foot and ankle include individual factors (length of work, BMI, and exercise habits), occupational factors (static position), variables of shoe characteristics (type of shoes, length of use of shoes, height of heels, and suitability shoe size) which has a significant association with musculoskeletal complaints on foot and ankle. Age variable has no significant relationship with musculoskeletal complaints on foot and ankle of SPG at Golden Market Jember.

Based on the results of the study, recommendation that can be given for the purpose of reducing musculoskeletal complaints on the foot and ankle of SPG at Golden Market Jember due to an incorrect selection of the characteristics of shoes used are to use the type of high heels, flat shoes, and high shoes that are better than $5 \mathrm{~cm}$ with a shoe size that fits and is comfortable on the foot.

\section{Reference}

Andini, F., 2015. Risk Factors of Low Back Pain in Workers. J Majority, 4(1), pp. 12-19.

Andreani, M. U. D., 2013. Work Attitudes Related to Subjective Complaints of Tailors on Patua Street Surabaya. Journal of Promkes, 1(2), p. 201-208.

Dewi , K. A. T., 2014. Descriptive Study: Prevalence and Distribution of Musculoskeletal Complaints in Elementary School Teachers, Users of High-Heeled Shoes in Klungkung District. E-Jurnal Medika Udayana, 3(5), pp.
572-582.

Dewi, N. K. N., 2013. Musculoskeletal Complaints on Sales Promotion Girl. Community Health, 1(1), pp. 143-150.

Law Number 13 Year 2003, concerning Manpower. In: Undang-Undang. Jakarta: Kementerian Tenaga Kerja dan Transmigrasi Republik Indonesia.

Kim, C., 2000. High-Heeled Shoes and Musculoskeletal Problem. Dynamic Chiropractic, Volume 18, p. 18.

Lestari, N. S., 2013. Description of the Risk Level of Complaints of Subjective Cumulative Trauma Disorders (CTDs) on Sales Promotion Girl (SPG) at the Shopping Center X in Depok City. National Public Health Journal, 1(1), pp. 1-8.

Megawati, D. U., 2014. Effect of Age on Dentist Performance in Public Health Centers in Yogyakarta Municipality. Journal of UMY, $1(1)$, p. 12.

Nicot , A. M., 2008. Women More at Risk of Musculoskleletal Disorder. European Observa-tory of Working Life, 1(1), p. 10.

$\mathrm{NIOSH}$, 1993. Comment from NIOSH on the occupational safety and health administration proposed rule on ergonomic safety and management US Department of Control and Service. [Online] Available at: http://www.cdc.gov [Accessed 1311 2017].

Nuryaningtyas, B. \& Tri , M., 2014. Risk Level Analysis of Musculoskeletal Disorders (MSDs) with The Rapid Upper Limbs Assessment (RULA) and Individual Characteristics of MSDs Complaints. The Indonesia Journal of Occupational Safety and Health, 3(2), pp. 160-169.

Occupational Safety and Health Administration (OSHA), 2007. E-Fact 9 - Work-Related Mus-culoskeletal Disorders (MSDs): An Introduction. European Agency for Safety and Health at Work. OSHA Europa, 1(9), pp. 1-9.

Permatasari, G. A., 2017. Effect of Wedge And Non Wedge Shoes On Gait and Balance. Journal of Kedokteran Diponegoro, 6(2), pp. 576-582.

Purba, N. P., 2015. Musculoskeletal Complaints Disorders (MSDS) on Sales Promotion Girl (SPG), Users of High Heels at Suzuya Medan Plaza in 2015. Journal of USU, 1(1), pp. 1-10.

Santoso, G., 2004. Ergonomics, Humans, Equipment and the Environment. Jakarta: Prestasi Pustaka.

Silva, A., Siqueira, G. \& Silva, G., 2013. Implication of High-Heeled Shoes on Body Posture of Adolescents. Rev Paul Pediatric, 31(2), pp. 
265-271.

Sinta, C. R., 2014. Analysis of the effect of high heels on foot pain of cosmetic salespeople in Manado. Journal of e-Biomedik (eBM), 2(1), pp. 1-6.

Slovak , A., Carder , M. \& Money , A., 2009. Work-Related Musculoskeletal Conditions: Evidence From The Thor Reporting System 2002-2005. Occupational Medicine, 59(1), pp. 447-453.

Smallwood, . L., Adam, J., Christoper, W. \& Wendi
, W., 2013. Influence Of Heel Type On Stride Length. E-journal Auburn University, 1(1), pp. 1-2.

Tarwaka, H., 2015. Industrial Ergonomics: Basics of Ergonomic Knowledge and Application at Work, Edition I. Surakarta: Harapan Press.

Ulfah, N., 2014. Work Attitudes and Risk of Musculoskeletal Disorders on Laundry Workers. Journal of Kesehatan Masyarakat Nasional, 8(7), pp. 311-318. 